\title{
A New, Highly Conductive, Lithium Salt/Nonionic Surfactant, Lyotropic Liquid-Crystalline Mesophase and Its Application
}

\author{
Cemal Albayrak, ${ }^{[a]}$ Atilla Cihaner, ${ }^{[b]}$ and Ömer Dag*[a]
}

Highly conductive electrolyte materials are an essential part of many electrochemical systems, such as fuel cells, solar cells, batteries, electrochromic devices, and next-generation renewable-energy sources. The growing diversity in batteries and electrochemical cells increases the demand for novel electrolyte materials. For instance, in solar-cell applications, an electrolyte material with high viscosity and low volatility is desirable, together with high ionic conductivity. ${ }^{[1]}$ Electrolytes can be solids, gels, or liquids depending on the application. Gel electrolytes are advantageous when the conductivity in the solid form is not sufficient or the leakage or vaporization of the liquid electrolyte is a problem. Gel electrolytes can be aqueous or non-aqueous depending on the application type. While in some battery systems aqueous gel electrolytes have no use-for example, in Li ion batteries-they can be used in many rechargeable batteries, ${ }^{[2]}$ electrochemical capacitors, ${ }^{[3]}$ solar cells,,${ }^{[4]}$ and so on. Liquid-crystal gel electrolytes have also been investigated and are considered to be an important class of ordered materials for the above applications. ${ }^{[5-14]}$

A lyotropic liquid-crystalline (LLC) mesophase is formed by two main constituents: an amphiphile and a solvent. Common solvents are water, ${ }^{[14]}$ organic liquids, ${ }^{[12]}$ or ionic liquids. ${ }^{[13]}$ LLC-based electrolytes offer many advantages, like rigidity and high ionic mobility and can be an alternative to polymer electrolytes. Solvent-free LC systems (thermotropic LC) usually have low ionic conductivities at room temperature, typically around $10^{-6} \mathrm{~S} \mathrm{~cm}^{-1},{ }^{[5-11]}$ whereas solvent-containing LLC systems have room-temperature ionic conductivities around $10^{-3} \mathrm{~S} \mathrm{~cm}^{-1} \cdot \cdot^{14,15]}$ Usually high ionic conductivity in solvent-free LC electrolyte systems is achieved at high temperatures, that is, $150^{\circ} \mathrm{C}$ and above. ${ }^{[16]} \mathrm{Re}-$ cently we have shown that transition-metal aqua complex salts $\left(\left[\mathrm{M}\left(\mathrm{H}_{2} \mathrm{O}\right)_{6}\right] \mathrm{X}_{2}\right.$; in which $\mathrm{M}^{\mathrm{II}}$ is a transition-metal cation

[a] C. Albayrak, Prof. Ö. Dag

Department of Chemistry, Bilkent University

06800, Ankara (Turkey)

Fax: (+90)312-266-4068

E-mail:dag@fen.bilkent.edu.tr

[b] Prof. A. Cihaner

Department of Chemical Engineering and Applied Chemistry Atilim University 06836, Ankara (Turkey)

Supporting information for this article is available on the WWW under http://dx.doi.org/10.1002/chem.201103705. and $\mathrm{X}$ is a suitable counterion), which have melting points close to room temperature, can also be used as solvents in the self-assembly process of some surfactants. ${ }^{[17-19]}$ The LLC mesophases of molten transition-metal-salt aqua complexes have important physical properties, such as high thermal stability (between 83 and $383 \mathrm{~K}$ ), high ionic conductivity (room-temperature conductivities close to $2.0 \times 10^{-4} \mathrm{~S} \mathrm{~cm}^{-1}$ ), and nonvolatility. ${ }^{[18]}$

A highly concentrated aqueous electrolyte solution of an alkali metal salt can also act as a solvent in the assembly process of oligo(ethylene oxide) type surfactants, in which the highly concentrated electrolyte solution can be considered as an analogue of a molten salt. ${ }^{[20]}$ Their similarities arise due to strong ion-dipole (salt-water) interactions at high salt concentrations (highly concentrated refers to water/salt mole ratios of less than 8 in the case of lithium salts) and as a consequence, the heat of vaporization of water sharply increases. ${ }^{[20]}$

In this contribution, we have investigated the phase behavior and ionic conductivity of a new class of hydrated-salt/ surfactant mesophase, namely; $\mathrm{LiNO}_{3}-\mathrm{H}_{2} \mathrm{O}-\mathrm{C}_{12} \mathrm{EO}_{10}$, LiCl$\mathrm{H}_{2} \mathrm{O}-\mathrm{C}_{12} \mathrm{EO}_{10}$, and $\mathrm{LiClO}_{4}-\mathrm{H}_{2} \mathrm{O}-\mathrm{C}_{12} \mathrm{EO}_{10}$ systems, in which $\mathrm{C}_{12} \mathrm{EO}_{10}$ is $\mathrm{C}_{12} \mathrm{H}_{25}\left(\mathrm{OCH}_{2} \mathrm{CH}_{2}\right)_{10} \mathrm{OH}$. The mesophase is a collaborative assembly of a hydrated salt species in the liquid phase and surfactant molecules. Earlier studies on saltwater-surfactant mesophases focus on the effect of salts on the phase behavior of surfactants in dilute aqueous solutions $\left(18-\infty\right.$, water/salt mole ratio). ${ }^{[1-26]}$ Here, we demonstrate that as little as two water molecules per molecule of lithium salt is sufficient to form a LLC mesophase. At such a low water and high salt concentrations, the bulk properties of water are altered by the salt-water interactions and the saltwater couple collaboratively acts as the solvent in the LLC mesophase. An important outcome of the salt-water interaction is that the LLC mesophase is stable under ambient atmospheric conditions for years (see Supporting Information) and displays high ionic conductivity over a broad temperature range.

The LLC samples were prepared by adding each ingredient: salt $\left(\mathrm{LiNO}_{3}, \mathrm{LiCl}\right.$, or $\left.\mathrm{LiClO}_{4}\right)$, surfactant $\left(\mathrm{C}_{12} \mathrm{EO}_{10}\right)$, and water in the required amounts and the resulting mixture was then homogenized by constant shaking in a shaking water bath at $60-110^{\circ} \mathrm{C}$ for $24 \mathrm{~h}$. Under ambient conditions, the amount of water in the samples depends on the temperature, relative humidity, and the amount of salt in the mesophase, but always enough water remains in the samples to 
(A)

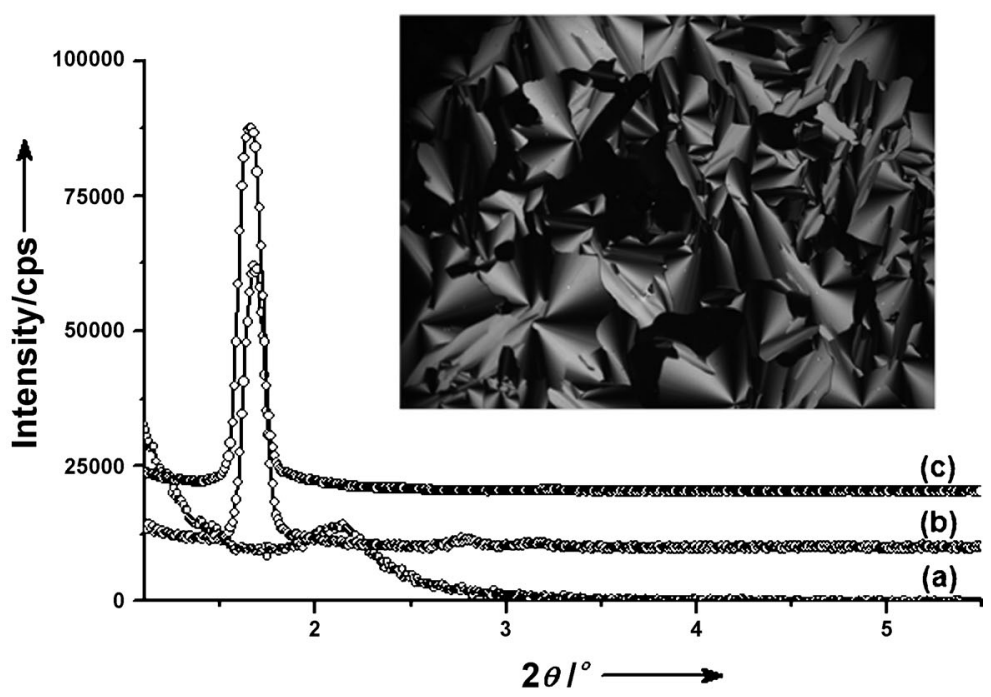

(B)

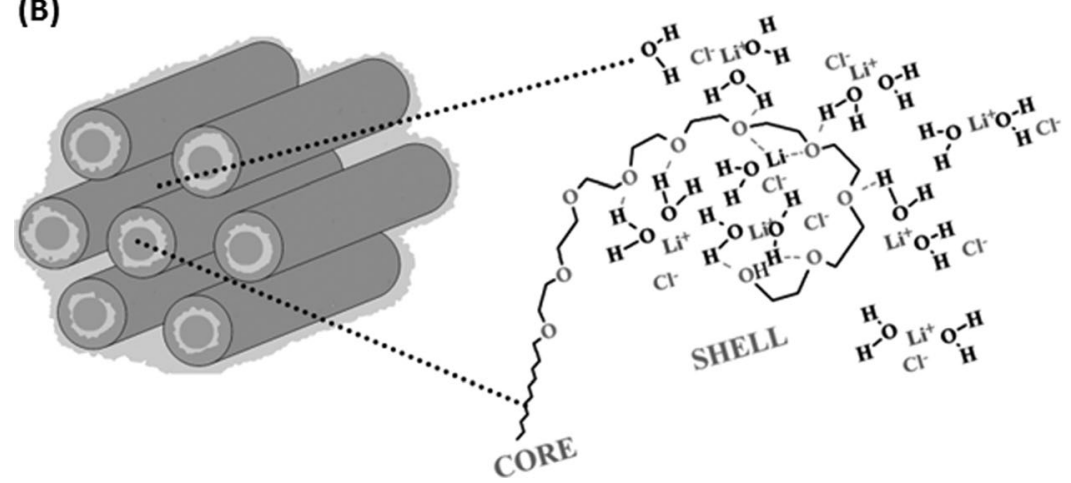

Figure 1. A) The XRD patterns for the samples with the composition a) $\mathrm{LiClO}_{4}-\mathrm{H}_{2} \mathrm{O}-\mathrm{C}_{12} \mathrm{EO}_{10}$, b) $\mathrm{LiCl}-\mathrm{H}_{2} \mathrm{O}$ $\mathrm{C}_{12} \mathrm{EO}_{10}$, and c) $\mathrm{LiNO}_{3}-\mathrm{H}_{2} \mathrm{O}-\mathrm{C}_{12} \mathrm{EO}_{10}$ systems and a polarized optical microscopy image in the inset. B) Schematic drawing of a normal hexagonal mesophase.

ensure stability of the LLC mesophases (see Supporting Information).

Figure 1A shows a set of powder X-ray diffraction (XRD) patterns of the liquid crystalline mesophases of the $\mathrm{LiNO}_{3}-$ $\mathrm{H}_{2} \mathrm{O}-\mathrm{C}_{12} \mathrm{EO}_{10}$, $\mathrm{LiCl}-\mathrm{H}_{2} \mathrm{O}-\mathrm{C}_{12} \mathrm{EO}_{10}$, and $\mathrm{LiClO}_{4}-\mathrm{H}_{2} \mathrm{O}-$ $\mathrm{C}_{12} \mathrm{EO}_{10}$ systems. The first diffraction lines correspond to the (100) plane of the hexagonal mesophase and provides a unit cell parameter $a$ of about $60.8,61.7$, and $47.7 \AA$ for the $\mathrm{LiCl}$, $\mathrm{LiNO}_{3}$, and $\mathrm{LiClO}_{4}$ systems, respectively. The inset shows a polarized optical microscopy (POM) image of a sample showing a classical fan-texture of a hexagonal phase; all mesophases exhibit a similar fan texture. Figure $1 \mathrm{~B}$ shows a schematic representation of a normal hexagonal $\left(\mathrm{H}_{1}\right)$ LLC mesophase, in which the water-salt compositions are on the exterior of the rodlike surfactant domains.

A ternary phase diagram of the $\mathrm{LiNO}_{3}-\mathrm{H}_{2} \mathrm{O}-\mathrm{C}_{12} \mathrm{EO}_{10}$ system (shown in Figure 2) has been constructed using XRD and POM data from over 50 samples with a broad range of composition. A large region in the phase diagram belongs to a hexagonal LLC mesophase (marked $\mathbf{H}$ ). Note that the hexagonal mesophase exists between 37 and $65 \% \mathrm{w} / \mathrm{w}$ in the $\mathrm{H}_{2} \mathrm{O}-\mathrm{C}_{12} \mathrm{EO}_{10}$ mixture if no salt is added. The amount of $\mathrm{LiNO}_{3}$ can be as high as $33 \%$ w/w, which corresponds to a $\mathrm{LiNO}_{3} / \mathrm{C}_{12} \mathrm{EO}_{10}$ mole ratio of 7 and the amount of water can be as low as $12 \%$ w/w (corresponds to a water/salt mole ratio of 2) in the $\mathrm{LiNO}_{3}-\mathrm{H}_{2} \mathrm{O}-$ $\mathrm{C}_{12} \mathrm{EO}_{10}$ LLC mesophase. The two-phase regions that contain salt or surfactant crystals together with the $\mathbf{H}$ phase were not studied in detail and are marked with $\mathbf{2}$ and $\mathbf{3}$ in the phase diagram, respectively. At high water concentrations, micellar solution phases are observed (region $\mathbf{1}$ and towards higher water compositions). The broken line that divides the phase diagram into two (starting at $47 \%$ w/w $\mathrm{LiNO}_{3} / \mathrm{H}_{2} \mathrm{O}$ and ending at $100 \% \mathrm{w} / \mathrm{w}$ $\mathrm{C}_{12} \mathrm{EO}_{10}$ ), depicts the salt/surfactant weight ratio of a saturated aqueous $\mathrm{LiNO}_{3}$ solution at room temperature. Along this line, the weight ratio of $\mathrm{LiNO}_{3} /$ $\mathrm{H}_{2} \mathrm{O}$ is constant $(47 \% \mathrm{w} / \mathrm{w})$. Note that a considerable hexagonal region is present above this line. The higher intake of $\mathrm{LiNO}_{3}$ in the $\mathbf{H}$ phase relative to pure $\mathrm{H}_{2} \mathrm{O}$ is related to the confinement of the salt and water species in the hydrophilic domains of the hexagonal mesophase. ${ }^{[19]}$ The interaction of $\mathrm{Li}^{+}\left(\right.$or $\left.\mathrm{Li}^{+} \cdot x \mathrm{H}_{2} \mathrm{O}\right)$ with the surfactant head groups (see Supporting Information, the FTIR section) is a consequence of this confinement and, as a result, $\mathrm{LiNO}_{3}$ does not leach out, even above the solubility limit in pure water. Physical properties (such as melting

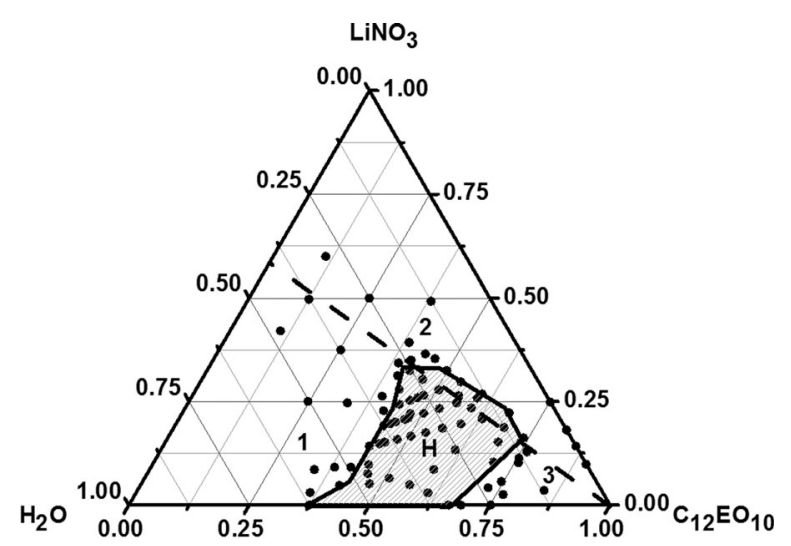

Figure 2. A ternary phase diagram of the $\mathrm{LiNO}_{3}-\mathrm{H}_{2} \mathrm{O}-\mathrm{C}_{12} \mathrm{EO}_{10}$ system. The black broken-line that divides the phase diagram into two corresponds to the weight ratio of $\mathrm{LiNO}_{3}$ to water in saturated $\mathrm{LiNO}_{3}$ solution at room temperature. Dots represent the prepared samples. 
point) of liquids can be altered when they are confined within mesoporous matrices. ${ }^{[27]}$ However, to the best of our knowledge this is one of the few examples ${ }^{[18]}$ of a soft confinement effect in which the solubility of a salt increases within liquid-like walls (soft domains).

It is also important to note that the phase behavior of the $\mathrm{LiCl}-\mathrm{H}_{2} \mathrm{O}-\mathrm{C}_{12} \mathrm{EO}_{10}$ system is very similar to that of the $\mathrm{LiNO}_{3}-\mathrm{H}_{2} \mathrm{O}-\mathrm{C}_{12} \mathrm{EO}_{10}$ system. At a moderate water/salt mole ratio (between 2 and 7), the salt/surfactant mole ratio can be varied between 2 and 8 to form stable LLC mesophases. The $\mathrm{LiClO}_{4}-\mathrm{H}_{2} \mathrm{O}-\mathrm{C}_{12} \mathrm{EO}_{10}$ system, however, shows a LLC mesophase in a very narrow region of salt/surfactant mole ratio, between 1.4 and 1.7 .

The choice of anion also greatly affects the water content of the samples, which are exposed to ambient laboratory conditions. Figure 3 shows the FTIR spectra of some sam-

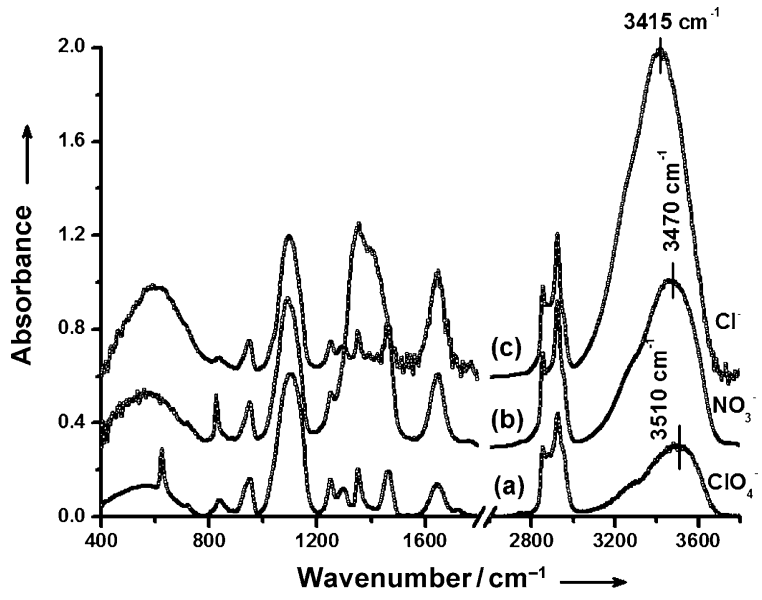

Figure 3. FT-IR spectra of the samples with compositions: a) $1.5 \mathrm{LiClO}_{4}$ $x \mathrm{H}_{2} \mathrm{O}-\mathrm{C}_{12} \mathrm{EO}_{10}$, b) $5 \mathrm{LiNO}_{3}-x \mathrm{H}_{2} \mathrm{O}-\mathrm{C}_{12} \mathrm{EO}_{10}$, and c) $5 \mathrm{LiCl}-x \mathrm{H}_{2} \mathrm{O}-$ $\mathrm{C}_{12} \mathrm{EO}_{10}$. The measurements were done under $25 \%$ relative humidity at room temperature.

ples under a $25 \%$ relative humidity. The higher intensity region-in the $v-\mathrm{OH}$ stretching region at around $3500 \mathrm{~cm}^{-1}$-in the spectrum of $5 \mathrm{LiCl}-\mathrm{H}_{2} \mathrm{O}-\mathrm{C}_{12} \mathrm{EO}_{10}$ indicates that the $\mathrm{LiCl}-\mathrm{H}_{2} \mathrm{O}-\mathrm{C}_{12} \mathrm{EO}_{10}$ system retains more water relative to the $\mathrm{LiNO}_{3}-\mathrm{H}_{2} \mathrm{O}-\mathrm{C}_{12} \mathrm{EO}_{10}$ system with the same salt/surfactant mole ratio. This is also evident in the $v-O H$ stretching frequencies that are more red-shifted in the $\mathrm{LiCl}$ systems, indicating a stronger $\mathrm{Cl}^{-} \cdots \mathrm{H}_{2} \mathrm{O}$ interaction relative to the $\mathrm{NO}_{3}{ }^{-} \cdots \cdot \mathrm{H}_{2} \mathrm{O}$ interaction (all the other variables like humidity, temperature, and composition were kept constant). The stronger $\mathrm{Cl}^{-} \cdots \mathrm{H}_{2} \mathrm{O}$ interaction also makes the $\mathrm{LiCl}-\mathrm{H}_{2} \mathrm{O}-\mathrm{C}_{12} \mathrm{EO}_{10}$ system more stable towards the changes in relative humidity (see Supporting Information). For example, the $\mathrm{LiCl}-\mathrm{H}_{2} \mathrm{O}-\mathrm{C}_{12} \mathrm{EO}_{10}$ samples lose very little water (possibly none) when the relative humidity is reduced down to $10 \%$ to test the sample stability (see Supporting Information for details). In the case of the $\mathrm{LiClO}_{4}$ mesophase, the intensity of the $v-\mathrm{OH}$ is the lowest (small amount of water), the peak frequency is the highest (weak $\mathrm{ClO}_{4}^{-}{ }^{-} \cdots \mathrm{H}_{2} \mathrm{O}$ inter action), and the stability is the lowest, see Figure $3 \mathrm{a}$. Spectra $b$ and $c$ are from the samples at equilibrium with atmosphere, while spectrum a is recorded from a freshly prepared $\mathrm{LiClO}_{4}$ sample. Note also that the $\mathrm{LiClO}_{4}$ samples are unstable under ambient conditions.

The ionic conductivities of the LLC mesophase of the $\mathrm{LiNO}_{3}-\mathrm{H}_{2} \mathrm{O}-\mathrm{C}_{12} \mathrm{EO}_{10}$ system with $\mathrm{LiNO}_{3} / \mathrm{C}_{12} \mathrm{EO}_{10}$ mole ratios of 5,6 , and 7 ; and that of the $\mathrm{LiCl}-\mathrm{H}_{2} \mathrm{O}-\mathrm{C}_{12} \mathrm{EO}_{10}$ system with a $\mathrm{LiCl} / \mathrm{C}_{12} \mathrm{EO}_{10}$ mole ratio of 5 were also measured as a function of temperature (Figure 4A; for details of the measurements see the Supporting Information). Note that these conductivities correspond to the total ionic conductivity of the samples and the transference numbers of different ionic species is not studied. The ionic conductivity shows a nearly Arrhenius-type relation with temperature. However, deviations increase as the temperature is lowered. Note that the system is highly conductive even below $0^{\circ} \mathrm{C}$, at which the samples still exhibit a LLC mesophase. The ionic conductivity of the LLC mesophase increases with an increasing water and salt content in the samples, see Figure $4 \mathrm{~B}$. The conductivities also increase as the salt composition increases (while keeping the water/salt mole ratio at 3) in both the $\mathrm{LiNO}_{3}$ and $\mathrm{LiCl}$ LLC systems, see Figure 4C. In

(A)

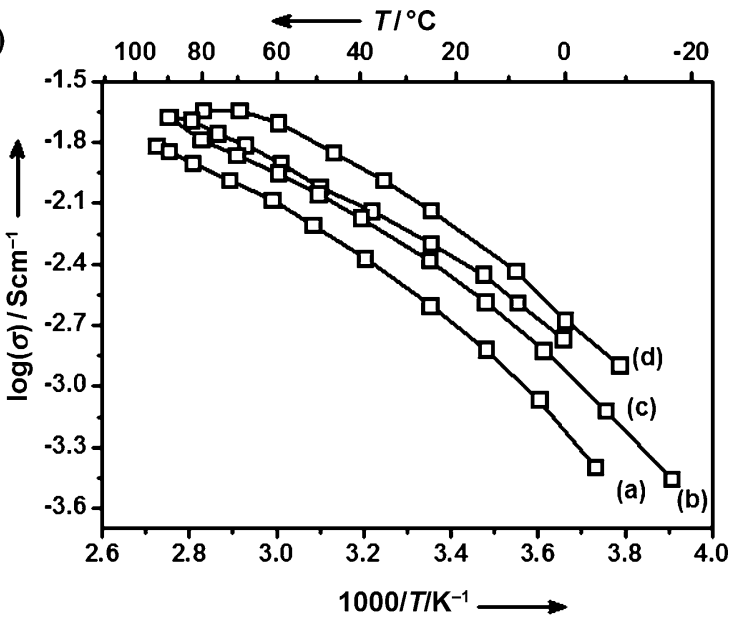

(B)

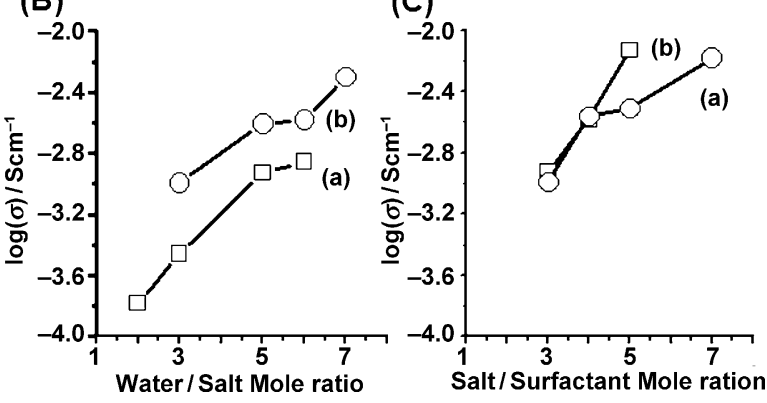

Figure 4. Conductivity: A) The logarithm of the ionic conductivity versus $1000 / T$ plots of the samples: a) $5 \mathrm{LiNO}_{3}-15 \mathrm{H}_{2} \mathrm{O}-\mathrm{C}_{12} \mathrm{EO}_{10}$, b) $6 \mathrm{LiNO}_{3}-$ $18 \mathrm{H}_{2} \mathrm{O}-\mathrm{C}_{12} \mathrm{EO}_{10}$, c) $7 \mathrm{LiNO}_{3}-21 \mathrm{H}_{2} \mathrm{O}-\mathrm{C}_{12} \mathrm{EO}_{10}$, and d) $5 \mathrm{LiCl}-25 \mathrm{H}_{2} \mathrm{O}-$ $\mathrm{C}_{12} \mathrm{EO}_{10}$. B) Conductivity versus water/salt mole ratio of a) $3 \mathrm{LiCl}-x \mathrm{H}_{2} \mathrm{O}-$ $\mathrm{C}_{12} \mathrm{EO}_{10}$, b) $5.0 \mathrm{LiNO}_{3}-x \mathrm{H}_{2} \mathrm{O}-\mathrm{C}_{12} \mathrm{EO}_{10}$. C) Conductivity versus salt/surfactant mole ratio of a) $x \mathrm{LiNO}_{3}-3 \mathrm{H}_{2} \mathrm{O}-\mathrm{C}_{12} \mathrm{EO}_{10}$, and b) $x \mathrm{LiCl}-3 \mathrm{H}_{2} \mathrm{O}-$ $\mathrm{C}_{12} \mathrm{EO}_{10}$. 
this investigation, the highest conductivities that have been recorded are around $7.0 \times 10^{-3} \mathrm{Scm}^{-1}$ at room temperature and $2.0 \times 10^{-2} \mathrm{~S} \mathrm{~cm}^{-1}$ at $90^{\circ} \mathrm{C}$. These values are quite high for gel electrolytes, but low compared to aqueous solutions of lithium salts (see Supporting Information section).

The $4 \mathrm{LiCl}-16 \mathrm{H}_{2} \mathrm{O}-\mathrm{C}_{12} \mathrm{EO}_{10}$ LLC gel has also been used as an electrolyte material in an electrochromic device that was made up of two electrochromic polymers-poly(4,7-di2,3-dihydrothieno[3,4-b][1,4]dioxin-5-yl-2,1,3-benzoselenadiazole) (A) and poly(3,4-ethylenedioxythiophene) (B) separately coated on indium tin oxide (ITO) electrodes in tetrabutylammonium perchlorate $(0.1 \mathrm{M})$ dissolved in dichloromethane and $\mathrm{LiClO}_{4}(0.1 \mathrm{M})$ dissolved in acetonitrile, respectively. ${ }^{[28]}$ The polymers $\mathbf{A}$ and $\mathbf{B}$ are green and dark blue in their neutral states, respectively, and transmissive sky blue upon oxidation. This electrochromic device, constructed using these two electrodes and separated from each other by our LLC gel electrolyte, was kept at room temperature for $1 \mathrm{~h}$ under ambient conditions to equilibrate. The electronic and optical properties of the device were recorded by switching between the two colored states (reference and counter-electrodes shorted together) by means of a square-wave potential method. ${ }^{[29]}$ Under a square-wave potential input of -1.0 and $+1.2 \mathrm{~V}$ with a residence time of $4 \mathrm{~s}$ at each potential, the electrical response of the device was simultaneously recorded.

An ideal electrochromic device should switch back and forth between the two oxidation states with a certain response time and also be stable upon multiple switching (long cycle life). Figure 5 depicts the stability and the switching behavior of the device. The switching time (0.4$0.5 \mathrm{~s}$ ), robustness, and the stability of the system suggest that the LLC gel electrolyte is a promising candidate for the electrochromic devices and optical displays. For example, the device continues to keep its redox stability (Figure 5), retaining $69 \%$ of its electronic activity after 5000th switch. Also, during this process, the device retained $44.6 \%$ of its

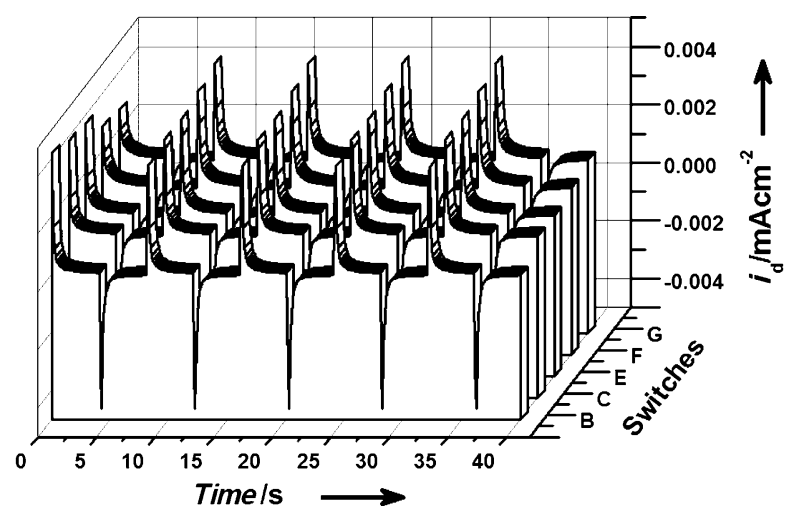

Figure 5. Electrochromic device performance: Current profile of a sample $4 \mathrm{LiCl}-16 \mathrm{H}_{2} \mathrm{O}-\mathrm{C}_{12} \mathrm{EO}_{10}$ sandwiched between ITO glasses, coated with poly(4,7-di-2,3-dihydrothieno[3,4-b][1,4]dioxin-5-yl-2,1,3-benzoselenadiazole) and poly(3,4-diethleyedioxythiophene) during 5000 switches. Switch cycles are B) 1-5, C) 996-1000, E) 2996-3000, F) 3996 4000, and G) 4996-5000. optical activity at $610 \mathrm{~nm}$, Figure S6 in the Supporting Information. The performance of the LLC mesophase as a gel electrolyte is as good as a commonly used organic-solventbased gel electrolyte consisting of propylene-carbonate, acetonitrile, poly(methyl metacrylate), and a supporting electrolyte. ${ }^{[30]}$ The low cost and low toxicity of the hydrated lithium salt LLC mesophases relative to the organic-based gel electrolytes make them advantageous in many applications, although their aqueous nature restricts them from being used in water-sensitive applications (for example, Li batteries).

The hydrated salt/surfactant, $\mathrm{LiNO}_{3}-\mathrm{H}_{2} \mathrm{O}-\mathrm{C}_{12} \mathrm{EO}_{10}, \mathrm{LiCl}-$ $\mathrm{H}_{2} \mathrm{O}-\mathrm{C}_{12} \mathrm{EO}_{10}$, and $\mathrm{LiClO}_{4}-\mathrm{H}_{2} \mathrm{O}-\mathrm{C}_{12} \mathrm{EO}_{10}$, systems form LLC mesophases over a broad range of compositions. Therefore, the salt-surfactant mesophases is extended to non-transition-metals, for which salt-water interactions are distinctly different in nature as compared to transition-metal salts. At very low water/salt mole ratios, the interactions within the salt-water couple organize the surfactant molecules into a LLC mesophase. In the $\mathrm{LiNO}_{3}-\mathrm{H}_{2} \mathrm{O}-\mathrm{C}_{12} \mathrm{EO}_{10}$ system, the salt/water mole ratio can be nearly 2.2 times higher as compared to a saturated $\mathrm{LiNO}_{3}$ aqueous solution. This is due to the interaction of the salt-water couple with the hydrophilic ethylene oxide domains and the confinement effect. ${ }^{[18]}$ These findings are fundamentally important in colloid chemistry, in which little or no attention has been given to the surfactant self-assembly with molten metal salts as the solvent. Moreover, these findings suggest that any highly concentrated solution of a hydrated metal salt that has high heat of vaporization in the confined domains of the LLC mesophase is a suitable solvent for self-assembly. The $\mathrm{LiNO}_{3}{ }^{-}$and LiCl-containing LLC mesophases have a high resistance to evaporation and display high ionic conductivities over a broad temperature range. The $\mathrm{LiNO}_{3} \mathrm{LLC}$ mesophase has higher ionic conductivity among the investigated LLC mesophases, but the LiCl LLC mesophases are stable at higher water concentration and may have higher ionic conductivity in dilute conditions. Moreover, the $\mathrm{LiCl}$ system is more stable at lower humidity. Therefore, the new lithium-containing LLC mesophase can be a good candidate as a new, cheap, and environmentally friendly electrolyte material for non-water-sensitive electrochemical applications, for which a highly conductive gel phase is required.

\section{Experimental Section}

Sample preparation: The sample preparation requires only the addition of each ingredient, salt, surfactant $\left(\mathrm{C}_{12} \mathrm{EO}_{10}\right)$, and water in the required amounts and homogenization by constant shaking in a shaking water bath. The samples were homogenized in closed glass vials between 60 and $110^{\circ} \mathrm{C}$ for $24 \mathrm{~h}$. Under ambient conditions, the amount of water remaining in the samples depends on the temperature, relative humidity, and the salt composition in the mesophase, but enough remains to ensure stability of the LLC mesophases. A sample with the composition $5 \mathrm{LiCl} /$ $15 \mathrm{H}_{2} \mathrm{O} / \mathrm{C}_{12} \mathrm{EO}_{10}$ was prepared by placing $\mathrm{C}_{12} \mathrm{EO}_{10}(1.00 \mathrm{~g}), \mathrm{LiCl}(0.330 \mathrm{~g})$ and $\mathrm{H}_{2} \mathrm{O}(0.431 \mathrm{~g})$ in a $20 \mathrm{~mL}$ vial. The closed vial was constantly shaken in hot water bath $\left(80-100^{\circ} \mathrm{C}\right)$ for at least $24 \mathrm{~h}$. 
Characterization: The XRD patterns were recorded on a Rigaku Miniflex diffractometer using a high power $\mathrm{Cu}_{\mathrm{K} \alpha}$ source operating at $30 \mathrm{kV} /$ $15 \mathrm{~mA}$. The room-temperature measurements were carried out by spreading the samples on glass slides. The POM images were obtained in transmittance mode on a ZEISS Axio Scope A1 polarizing optical microscope with a Linkam LTS350 temperature controlling stage attached to the microscope. Temperature control was done using a LinkamT95-LinkPad temperature programmer attached to the stage. The FTIR spectra were recorded using a Bruker Tensor 27 model FTIR spectrometer. A Digi Tect TM DLATGS detector was used with a resolution of $4.0 \mathrm{~cm}^{-1}$ in the $400-4000 \mathrm{~cm}^{-1}$ range. The spectra were recorded by either spreading the samples on silicon wafers or sandwiching them between two silicon wafers to avoid the evaporation of water. FT-IR spectra were collected with 64 scans for sandwiched samples and 8 scans for non-sandwiched ones. The AC impedance conductivity measurements were carried out using a Gamry G750 potentiostat/galvanostat by using a home-made conductivity cell (closed to the atmosphere) equipped with two stainlesssteel electrodes (see the Supporting Information for details). The cell constant for the conductivity cell was determined to be as $0.59 \mathrm{~cm}^{-1}$ by using a standard solution of $\mathrm{KCl}$ at room temperature. The conductivity measurements at low temperatures were done by immersing the conductivity cell in an ethanol bath, which was temperature controlled with a Thermo HAAKE EK 45/90 cryostat. The measurements at or above room temperature were performed by immersing the conductivity cell in a hot water bath. In all conductivity measurements, resistance data were recorded after the equilibration of the sample temperature with the bath temperature.

\section{Acknowledgements}

The financial support of TÜBİTAK under the project 110T813 and the Turkish Academy of Science (TÜBA) are deeply appreciated.

Keywords: electrochromic devices • electrolyte materials • ionic conductivity $\cdot$ liquid crystals $\cdot$ lithium

[1] Y. Bai, Y. M. Cao, J. Zhang, M. Wang, R. Z. Li, P. Wang, S. M. Zakeeruddin, M. Grätzel, Nat. Mater. 2008, 7, 626-630.

[2] J. Y. Song, Y. Y. Wang, C. C. Wan, J. Power Sources 1999, 77, 183 197.

[3] N. A. Choudhury, S. Sampath, A. K. Shukla, Energy Environ. Sci. 2009, 2, 55-67.

[4] C. H. Law, S. C. Pathirana, X. O. Li, A. Y. Anderson, P. R. F. Barnes, A. Listorti, T. H. Ghaddar, B. C. O'Regan, Adv. Mater. 2010, 22, 4505-4509.
[5] K. Hoshino, K. Kanie, T. Ohtake, T. Mukai, M. Yoshizawa, S. Ujiie, H. Ohno, T. Kato, Macromol. Chem. Phys. 2002, 203, 1547-1555.

[6] P. Judeinstein, F. Roussel, Adv. Mater. 2005, 17, 723-727.

[7] K. Kishimoto, M. Yoshio, T. Mukai, M. Yoshizawa, H. Ohno, T Kato, J. Am. Chem. Soc. 2003, 125, 3196-3197.

[8] J. Li, K. Kamata, M. Komura, T. Yamada, H. Yoshida, T. Iyoda, Macromolecules 2007, 40, 8125-8128.

[9] T. Ohtake, Y. Takamitsu, K. Ito-Akita, K. Kanie, M. Yoshizawa, T. Mukai, H. Ohno, T. Kato, Macromolecules 2000, 33, 8109-8111.

[10] M. Yoshio, T. Kagata, K. Hoshino, T. Mukai, H. Ohno, T. Kato, J. Am. Chem. Soc. 2006, 128, 5570-5577.

[11] P. M. Simone, T. P. Lodge, ACS Appl. Mater. Interfaces 2009, 1, 2812-2820.

[12] A. Ray, J. Am. Chem. Soc. 1969, 91, 6511-6512.

[13] K. Binnemans, Chem. Rev. 2005, 105, 4148-4204.

[14] P. L. Kerr, S. A. Miller, R. K. Shoemaker, B. J. Elliott, D. L. Gin, J. Am. Chem. Soc. 2009, 131, 15972-1593.

[15] H. Shimura, M. Yoshio, K. Hoshino, T. Mukai, H. Ohno, T. Kato, J. Am. Chem. Soc. 2008, 130, 1759-1765.

[16] K. Kishimoto, T. Suzawa, T. Yokota, T. Mukai, H. Ohno, T. Kato, J. Am. Chem. Soc. 2005, 127, 15618-15623.

[17] Ö. Çelik, Ö. Dag, Angew. Chem. 2001, 113, 3915-3919; Angew. Chem. Int. Ed. 2001, 40, 3800-3803.

[18] C. Albayrak, N. Özkan, Ö. Dag, Langmuir 2011, 27, 870-873.

[19] C. Karakaya, Y. Türker, C. Albayrak, Ö. Dag, Chem. Mater. 2011, 23, 3062-3071.

[20] H. Braunstein, J. Braunstein, P. T. Hardesty, J. Phys. Chem. 1973, 77, 1907-1914.

[21] R. Dong, J. Hao, Chem. Rev. 2010, 110, 4978-5022.

[22] T. Inoue, Y. Yokoyama, L.-Q. Zheng, J. Colloid Interface Sci. 2004, 274, 349-353.

[23] T. Iwanaga, M. Suzuki, H. Kunieda, Langmuir 1998, 14, 5775-5781.

[24] D. J. Mitchell, G. J. T. Tiddy, L. Waring, T. Bostock, M. P. McDonald, J. Chem. Soc. Faraday Trans. 1 1983, 79, 975-1000.

[25] K. Weckström, A. C. Papageorgiou, J. Colloid Interface Sci. 2007, $310,151-162$.

[26] L. Zheng, H. Minamikawa, K. Harada, T. Inoue, G. G. Chernik, Langmuir 2003, 19, 10487-10494.

[27] D. Vargas-Florencia, O. Petrov, I. Furo', J. Phys. Chem. B 2006, 110, 3867-3870.

[28] A. Cihaner, F. Alg1, Adv. Funct. Mater. 2008, 18, 3583-3589.

[29] A. Cihaner, F. Alg1, Electrochim. Acta 2008, 53, 2574-2578.

[30] A. Cirpan, A. A. Argun, C. R. G. Grenier, B. D. Reeves, J. R. Reynolds, J. Mater. Chem. 2003, 13, 2422-2428. 